\title{
A INVESTIGAÇÃO CRIMINAL REALIZADA PELO ÓRGÃO DO MINISTÉRIO PÚBLICO EM ANALOGIA COM O SISTEMA DE FREIOS E CONTRAPESOS
}

\author{
Tamila Antunes da Costa, Wesley da Costa Santos \\ Universidade do Oeste Paulista - UNOESTE, Curso de Direito, Presidente Prudente, SP. E-mail: \\ wesleycosta.ti@gmail.com
}

\begin{abstract}
RESUMO
No presente trabalho, buscamos inicialmente expor de forma teórica as atividades explícitas da Polícia Judiciária, bem como, do Ministério público em composição com a Teoria dos Poderes Implícitos como fundamentação para posicionamentos doutrinários. Nossa intenção com tais informações foi a de realizar uma analogia direta com as investigações criminais que são arroladas por iniciativa do Ministério Público com o Sistema de Freios e Contrapesos, o qual foi e é elementar para a conceituação da tripartição dos poderes estatais. Assim, o vigente estudo ponderou-se em pesquisas bibliográficas, leituras e fichamentos, da mesma maneira que foi respaldado por procederes da jurisprudência brasileira acerca do assunto. Finalmente, apresentamos as imprecisões e contrariedades na interpretação da norma no âmbito investigatório.

Palavras-chave: Investigação, Teoria, Freios, Contrapesos, Sistema.
\end{abstract}

\section{THE CRIMINAL INVESTIGATION CARRIED OUT BY THE PUBLIC PROSECUTOR'S OFFICE IN ANALOGY WITH THE CHECKS AND BALANCES SYSTEM}

\begin{abstract}
This paperwork intention, initially, is to expose, theoretically, the activities of the Judiciary Police as well as the Public Prosecutors composing with the theory of the implicit powers as ground for indoctrinated positions. This paperwork uses this line of thought and information to make a direct analogy with the criminal investigations that are listed by the Public Prosecutors' initiative with the checks and balances systems. This line was essential to compose the concept of the three state powers composition. Therefore this case pondered in the bibliographical researches, readings and annotations in the same direction that it was supported by Brazilian jurisprudence of the theme. Finally we present inaccuracies and setbacks on the norms interpretations of the investigation field.
\end{abstract}

Keywords: Investigation, Theory, checks, balances, system 


\title{
INTRODUÇÃO
}

A Constituição Federal de 1988 no seu artigo 129 conferiu ao Ministério Público várias funções institucionais, elencadas em seus diversos incisos. Ao dispor destas atribuições não deixou expressamente clara a possibilidade do poder investigatório deste órgão, gerando assim, um conflito de opiniões em aberto e a fundamentação para a aplicação da Teoria dos Poderes Implícitos.

Como se não bastasse, no artigo 144 foi atribuído à polícia judiciária (polícia civil e federal) a apuração de infrações penais contra a ordem política e social, resultando em uma controvérsia de interesses sobre as investigações criminais.

Deste modo, nossa pesquisa se pautará na análise de nossa atual situação junto ao conceito do Checks and Balances para um posicionamento acerca do tema.

\section{METODOLOGIA}

Toda a metodologia utilizada para o presente trabalho se respaldou em pesquisas bibliográficas, sites oficiais da área jurídica e fichamentos para identificar causas, importância ou forma de aplicação do assunto em tema. Utilizamos o caráter dedutivo para a pesquisa, como bem salienta Gil:

\begin{abstract}
O método dedutivo, de acordo com a acepção clássica, é o método que parte do geral, a seguir, desce ao particular. Parte de princípios reconhecidos como verdadeiros e indiscutíveis e possibilita chegar a conclusões de maneira puramente formal, isto é, em virtude unicamente de sua lógica. E o método proposto pelos racionalistas (Descartes, Spinoza, Leibniz), segundo os quais só a razão é capaz de levar ao conhecimento verdadeiro, que decorre de princípios a priori evidentes e irrecusáveis. (GIL, 2012, p.9)
\end{abstract}

\section{RESULTADOS}

Os resultados do presente trabalho parte da análise dos fatos expostos e na tentativa de trazer coerência no que está devidamente positivado em nossa Constituição, fornecendo base para o exercício do controle constitucional sobre as atividades dos órgãos estatais, ostentando a validade dos princípios que norteiam os limites das ações do Estado.

\section{DISCUSSÃO}

\section{FUNÇÕES EXPLICÍTAS DA POLÍCIA JUDICIÁRIA BRASILEIRA}

As funções típicas da Polícia Judiciária tem previsão no artigo 144 da Constituição Federal, que no seu Parágrafo 10 , inciso IV, relata que a polícia judiciária é exercida a nível nacional pela polícia Federal e a nível estadual pelas polícias civis. Sendo ela um órgão de segurança pública do Estado, devendo agir para apurar as infrações penais e sua autoria por meio das investigações criminais, onde são propriamente realizadas no curso do Inquérito Policial, que tem por objetivo captar elementos necessários, colher, juntar elementos relativos para conseguir alcançar a materialidade e indícios de autoria de um crime, sendo o Estado o responsável para apurar esses procedimentos que de certa forma são informativos e preparatórios para a ação penal e promover assim a responsabilidade penal do infrator. Em conjunto com a Constituição Federal o Código de Processo Penal no seu artigo 4을 deixa claro que o papel da polícia judiciária será exercido pelas autoridades policiais em suas respectivas localidades, as quais são responsáveis em apurar as infrações penais e suas diligências.

\section{FUNÇÕES EXPLICÍTAS DO MINISTÉRIO PÚBLICO}

O Ministério Público é um órgão permanente e essencial à função jurisdicional do Estado, sendo atribuída a função de defender a ordem jurídica, o regime democrático e os interesses sociais e individuais indisponíveis. Os interesses sociais são os coletivos e difusos sendo os patrimônios históricos, paisagísticos, meio ambientes, criança e adolescente, consumidor, 
portadores de deficiência, entre outros. Já os interesses individuais indisponíveis são aqueles próprios de cada pessoa, do qual o indivíduo jamais poderá abrir mão dele, como a liberdade, a saúde, educação, à vida. Vale ressaltar que o Ministério Público não intervém em todas as ações da justiça, apenas quando envolve partes que lhe cabe defender. Foi atribuído claramente ao Ministério Público promover ação civil pública e ação penal pública, ou seja, é certo que cada instituição do Ministério Público pode dar início a essas ações em sua atuação. Outra função atribuída a ele é exercer o controle externo da atividade policial, zelar pelo respeito dos serviços de relevância pública, requisitar diligências investigatórias e instaurar inquérito policial.

\section{TEORIA DOS PODERES IMPLÍCITOS}

Desenvolvida nos Estados Unidos em 1819, objetivamente entendemos que "quem pode mais, pode menos", assim, sendo o Ministério Público responsável por propor ação, poderá, portanto, dirigir investigações criminais, que basicamente se refere aos caminhos necessários para a realização de sua atribuição fim (Art.129, I), que há de ser a de promover a ação penal pública, logo, segundo esta teoria, temos o indício de que para tal fim, poderá também o Ministério Público usar de todos os meios legais e possíveis para a realização desta atribuição. Finalmente, segundo os posicionamentos que defendem esta corrente, nossa Constituição de 88 não atribui como monopólio da Polícia Judiciária o processo investigatório, logo, este poderá ser tido como uma ação necessária e implícita do Ministério Público.

\section{POSICIONAMENTO DOUTRINÁRIOS E JURISPRUDENCIAIS ACERCA DA INVESTIGAÇÃO CRIMINAL REALIZADA PELO MINISTÉRIO PÚBLICO}

Os grandes doutrinadores brasileiros divergem sobre a possibilidade de o Ministério Público realizar diretamente diligências investigatórias. Os posicionamentos contrários baseiamse no artigo 144 da Constituição Federal de 88, o qual atribui a Polícia Judiciária o monopólio das investigações criminais, alegando ainda que há uma ausência de legalidade, ou seja, falta um fundamento legal explícito para que o Ministério Público exerça tal função, exatamente por este ser parte no processo penal, e como parte não poderia realizar a investigação criminal, pois esta há de ser dotada de imparcialidade, caso contrário, afetará a administração da justiça.

Um dos posicionamentos vem de Vieira da Silva et al. (2007, p.7-13), o qual deixa claro que a Constituição não atribuiu a investigação criminal como uma função do Ministério Público; já que esse procedimento efetuado pela Promotoria é ilegal e fere o princípio do devido processo legal, gerando assim, abuso de poder.

Nucci et al. (2010, p. 146) menciona que é "inviável que o promotor de justiça, titular da ação penal, assuma a postura de órgão investigador, substituindo a polícia judiciária e produzindo inquéritos visando a apuração de infrações penais e de sua autoria." O jurista diz que, se o Ministério Público dirigir a investigação e a instrução preparatória, poderá estar comprometendo a imparcialidade.

Os posicionamentos favoráveis diz que, quando o Ministério Público conduz uma investigação significa que está exercendo suas prerrogativas constitucionalmente asseguradas, contribuindo para uma melhor apuração do fato delituoso. Pacheco $(2008$, p. 187) diz que nossa Constituição Federal é clara no sentido de o Ministério Público investigar criminalmente, juntamente com as polícias, as comissões parlamentares de inquéritos, autoridades fiscais e administrativas. No entanto, quanto ao modo de investigar, o Ministério Público deve estrita obediência ao devido processo legal.

Para esses grandes doutrinadores não houve conflito algum entre as normas constitucionais, pois as normas possuem caráter principiológico, e que em seu artigo 144 não atribui exclusividade à Polícia Judiciária no que diz respeito às investigações de infrações penais. Segundo este, a atuação direta pelo Ministério Público pode conferir maior celeridade à atividade 
investigatória, permitindo melhor controle do agente com a prova e facilitando a formação do seu convencimento. Outro ponto que possui grande relevância no meio para tal posicionamento, é a alegação de que não é raro o envolvimento de policiais em episódios de corrupção ou mesmo com o crime organizado.

Quanto às fontes jurisprudenciais, o posicionamento atual do Supremo Tribunal Federal é favorável às investigações criminais realizadas por iniciativa do Ministério Público, contudo, este deixou bem elencado, requisitos que precisam ser assistidos na realização destas, bem como:

- a inviolabilidade dos direitos e garantias fundamentais dos investigados;

- Todos os atos da investigação deverão ser praticados e documentados por membros do Ministério Público

- Deverá ser respeitadas as hipóteses de reserva constitucional de jurisdição quando estas versarem da prévia autorização do Poder Judiciário.

- Total observância às prerrogativas profissionais asseguradas por lei aos advogados;

- A total observância à Súmula 14 do Supremo Tribunal Federal

A razoabilidade do prazo para a realização da investigação

- E a dispor que as investigações realizadas pelo órgão, estejam sujeitas ao permanente controle do Poder Judiciário.

Ao longo da pesquisa identificamos que tanto o Supremo Tribunal Federal, quanto o Supremo Tribunal de Justiça, não caracteriza como inconstitucional a investigação criminal arrolada pelo Ministério Público, tomando como base fundamental para tal posicionamento, a teoria dos poderes implícitos, já supracitada no presente trabalho.

Neste sentido: STF. Plenário. RE 593727/MG, rel. Orig. Min. Cezar Peluso, red. P/ o acórdão Min. Gilmar Mendes, julgado em 14/5/2015 (repercussão geral) (Info 785).

Tese fixada pelo STF e aplicada para casos semelhantes:

“O Ministério Público dispõe de competência para promover, por autoridade própria, e por prazo razoável, investigações de natureza penal, desde que respeitados os direitos e garantias que assistem a qualquer indiciado ou a qualquer pessoa sob investigação do Estado, observadas, sempre, por seus agentes, as hipóteses de reserva constitucional de jurisdição e, também, as prerrogativas profissionais de que se acham investidos, em nosso País, os advogados (Lei 8.906/1994, art. 7으, notadamente os incisos I, II, III, XI, XIII, XIV e XIX), sem prejuízo da possibilidade - sempre presente no Estado democrático de Direito - do permanente controle jurisdicional dos atos, necessariamente documentados (Enunciado 14 da Súmula Vinculante), praticados pelos membros dessa Instituição."

Assim, na ausência de lei própria, o Conselho Nacional do Ministério Público editou a Resolução 13/2006 disciplinando a instauração e tramitação do procedimento investigatório criminal realizado pelo Ministério Público, a qual posteriormente foi alvo de uma ADI proposta pela Ordem dos Advogados do Brasil sob fundamento de que o poder de legislar sobre matéria de Direito Processual é privativo a União, logo, um órgão independente e separado dos três poderes que sustentam nossa República Democrática versar de tal matéria não é admissível em hipótese alguma.

\section{O SISTEMA DE FREIOS E CONTRAPESOS}

O início para a fundamentação do Sistema de Freios e Contrapesos veio da Grécia e Roma antigas, a partir de obras do filósofo Aristóteles, seguidor de Platão, o qual foi fonte base para que posteriormente Locke e Montesquieu pudessem sistematizar a teoria da separação dos poderes. Contudo, o sistema da tripartição estatal como entendemos hoje, veio com Montesquieu em sua obra rule of law, ou em português, o Espirito das Leis, vejamos:

“Quando, na mesma pessoa ou no mesmo corpo de Magistratura, o Poder Legislativo é reunido ao Executivo, não há liberdade. Porque pode temer-se que o mesmo Monarca ou mesmo o Senado faça leis tirânicas para executá-las tiranicamente. Também não haverá 
liberdade se o Poder de Julgar não estiver separado do Legislativo e do Executivo. Se estivesse junto com o Legislativo, o poder sobre a vida e a liberdade dos cidadãos seria arbitrário: pois o Juiz seria o Legislador. Se estivesse junto com o Executivo, o Juiz poderia ter a força de um opressor. Estaria tudo perdido se um mesmo homem, ou um mesmo corpo de principais ou nobres, ou do Povo, exercesse estes três poderes: o de fazer as leis; o de executar as resoluções públicas; e o de julgar os crimes ou as demandas dos particulares". (MONTESQUIEU et al, 2000, p.167).

Logo, tal conceituação foi a via utilizada para balizar poderes absolutos de toda a Idade Moderna em diversas revoluções, nos deixando um rico histórico prático não só nisto, mas também na forma de fazer governo em sua evolução na política inglesa com o advento do veto e do impeachment, estabelecendo diversas medidas de controle sobre as funções estatais.

Desta forma, nossa Constituição da República Federativa do Brasil de 1988 em seu artigo 2으, elevou a nível de cláusula pétrea, a separação dos poderes em nosso país, a fim de que não houvesse a usurpação de um poder sobre o outro, estabelecendo a harmonia entres estes ainda que independentes em suas atividades, na finalidade de garantir um controle recíproco, para que de tal modo, não seja violado o Estado Democrático de Direito.

\section{CONCLUSÃO}

Finalmente, entendemos que a ideia inicialmente teórica dos freios e contrapesos, estava intimamente ligada com o conceito de equilíbrio, cujo nenhum dos dois lados de uma mesma balança teriam pesos desiguais, assim, entendemos que a expressa ordem de funções estatais e fiscalização de sua execução deveria ser recíproco para todos os órgãos do Estado, gerando uma relação balanceada, onde cada membro do "Corpo Estado" trabalharia com liberdade, mas atento aos limites de suas atribuições.

Logo, a Constituição Federal foi clara em dizer que atribui ao Ministério Público a função de exercer o controle externo da atividade policial e não de substitui-la. Analisando tal situação fática em analogia com o Checks and Balances, podemos entender que ao conferir excesso de poder a um único órgão, o favorecemos obviamente a condutas abusivas.

Concluímos ainda que, não podemos sobrepor o implícito ao que está explícito, assim, se é clara a atribuição de uma função aos seus respectivos responsáveis não há que se pensar no que ficou subentendido, pois na verdade, nada ficou, e usar de generalizações dos posicionamentos doutrinários ou correntes que ignoram toda a fonte histórico-cultural é também ignorar o fato de que "todo conhecimento deriva da experiência" (LOCKE et tal).

\section{REFERÊNCIAS}

MONTESQUIEU, Charles de Secondat, Baron de. Do Espírito das Leis. 2a tiragem, São Paulo: Saraiva, 2000

NUCCl, Guilherme de Souza. Manual de processo penal e execução penal. 6a edição revista, atualizada e ampliada. São Paulo: Editora Revista dos Tribunais, 2010.

PACHECO, Denílson Feitoza. Direito processual penal: teoria, crítica e práxis. 5a edição revista e atualizada. Niterói, RJ: Impetus, 2008.

SILVA, Alberto José Tavares Vieira da. Investigação criminal: competência. São Luís: Lithograf, 2007

GIL, C. C., Métodos e Técnicas de Pesquisa Social. 6. Ed. São Paulo: Atlas, 2012 
http://www.brasil.gov.br/governo/2010/01/ministerio-publico Acesso em: 11 ago. 2018

http://www.migalhas.com.br/dePeso/16,MI31216,91041A+malsinada+Resolucao+n+13+do+CNM

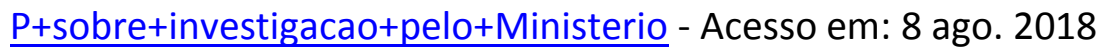

https://jus.com.br/artigos/33382/as-policias-judiciarias-e-suas-atribuicoes-na-investigacaocriminal - Acesso em: 07 ago. 2018

https://www.migalhas.com.br/dePeso/16,Ml8267,31047A+harmonia+dos+tres+poderes+e+a+co mposicao+do+Supremo+Tribunal - Acesso em: 14 ago. 2018

BRASIL. Constituição (1988). Constituição da República Federativa do Brasil. Brasília, DF: Senado Federal: Centro Gráfico, 1988. 292 p.

Código Processo Penal - Decreto-lei 3689/41 | Decreto-lei no 3.689, de 3 de outubro de 1941 